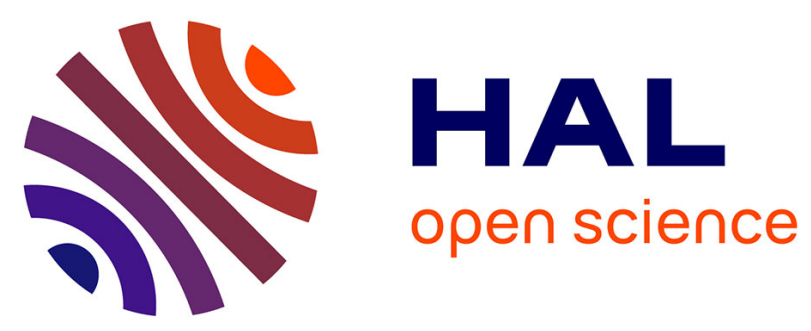

\title{
Reference Selection for an Active Ultrasound Wild Salmon Monitoring System
}

Gabriel Vasile, Guy d'Urso, Eric de Oliveira, Jérôme Guillet, Elena Lungu

\section{To cite this version:}

Gabriel Vasile, Guy d'Urso, Eric de Oliveira, Jérôme Guillet, Elena Lungu. Reference Selection for an Active Ultrasound Wild Salmon Monitoring System. OCEANS 2015 - OCEANS '15 MTS/IEEE. Sea Change: Dive into Opportunity, Oct 2015, Washington, DC, United States. hal-01257917

\section{HAL Id: hal-01257917 https://hal.science/hal-01257917}

Submitted on 18 Jan 2016

HAL is a multi-disciplinary open access archive for the deposit and dissemination of scientific research documents, whether they are published or not. The documents may come from teaching and research institutions in France or abroad, or from public or private research centers.
L'archive ouverte pluridisciplinaire HAL, est destinée au dépôt et à la diffusion de documents scientifiques de niveau recherche, publiés ou non, émanant des établissements d'enseignement et de recherche français ou étrangers, des laboratoires publics ou privés. 


\section{Reference Selection for an Active Ultrasound Wild Salmon Monitoring System}

\author{
Gabriel Vasile \\ Grenoble-Image-sPeech-Signal-Automatics Lab \\ CNRS / Grenoble-INP, UMR 5216 CNRS \\ Grenoble Cedex, France, F-38402 \\ Email: gabriel.vasile@gipsa-lab.grenoble-inp.fr
}

Guy d'Urso,

Eric de Oliveira

and Jérôme Guillet

EDF R\&D STEP / LNHE, Chatou, France

Email: guy.durso@edf.fr

\author{
Elena Lungu \\ SIGnal INformatics TEChnology \\ SIGINTEC \\ Nîmes, France, F-30000 \\ Email: elungu@ sigintec.fr
}

\begin{abstract}
This paper introduces the concept of automatic reference selection for active ultrasound wild salmon monitoring systems in turbulent underwater environments. A general in situ calibration procedure is proposed which allows grate improvements in terms of fish detection, identification and tracking capabilities.
\end{abstract}

\section{INTRODUCTION}

Generally, in dams or weirs (natural or artificial), hydro power plants have a certain impact on the water ecosystems especially for fish (migratory species) and aquatic organisms. Many fish species migrate on more or less extended areas, such as the wild salmon and eels which migrate several thousand of kilometers during their life cycle. The ecological continuity concept is defined as the possibility of free movement of animals (especially fish) and a free sediment transport. Considering the European regulation (European Water Frame Directive, EEL regulation), ecological continuity is a key criterion for fulfillment of the objectives of the regulation in rivers.

Fish passes and downstream bypass are of increasing importance for the restoration of free passage for fish and other aquatic species in rivers. Such devices are often the only way to make it possible for aquatic fauna to pass obstacles that block their up and down river journey. Efficiency or passability of these new and old structures must be quantified in situ. For this, various methods have been developed and used, such as trapping, telemetry or video counting. All these methods require manual and heavy processes (fish manipulation) or are dependent of the light and water quality.

Firstly, Spampinato et al. introduced in [1] an underwater imaging system for detecting fishes in Ken-Ding, Taiwan. The proposed imaging systems has three subcomponents: texture analysis, fish detection and fish tracking. The main inconvenient of such a system is the fact that it can operate during the day or with artificial illumination, only. Such a constraint is not applicable for wild salmons in monotonous regions since the smolts are mainly migrating during the night and any artificial illumination source will perturb them.

A second method for wild salmon counting is based on resistive measurements [2]. Using two electrodes, this monitoring system is measuring the conductivity fluctuations (slight decrease in amplitude) when a fish is passing through. Such techniques are well suited for calm underwater environments such as the fish elevators where no considerable turbulent follow is present. This is not well adapted for downstream smolts migrations in Alpine rivers.

Finally, An et al. recently introduced ultrasound for fish monitoring [3]: by using an ultrasound emitter, the acoustic signal scattered by the fish is analyzed using three underwater cameras. In this context, an active ultrasound fish monitoring system can efficiently contribute to detect, quantify and identify in the water column the fish species continuously.

This paper illustrates an example of active ultrasound wild salmon monitoring system which can be installed on mountainous rivers. The current system is composed of several acoustic barriers operating at multiple frequencies. According to Fig. 1-(b), each salmon passage will obstruct the acoustic propagation channel between the emitter and the receiver, which makes possible wild salmon monitoring. Each acoustic barrier acts as a conventional immersed wideband ultrasound system in bistatic configuration: the emitted waveform is a linear Hamming windowed chirp.

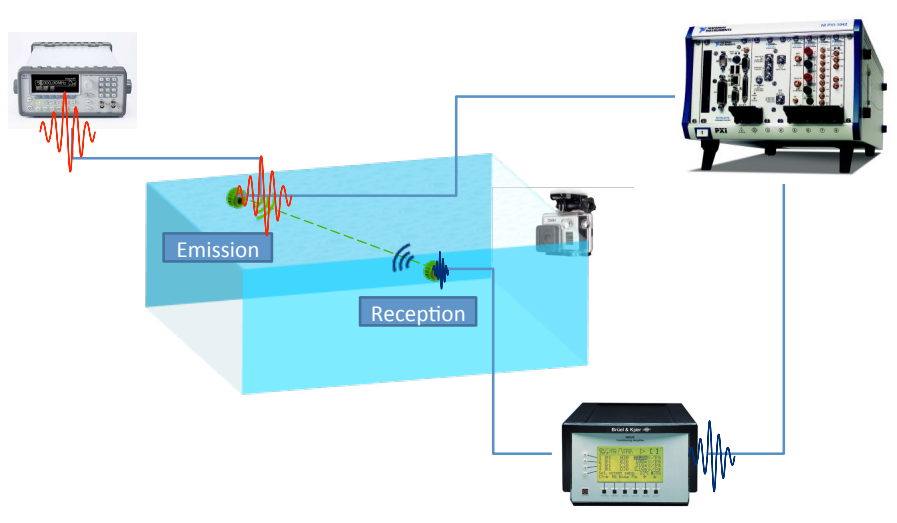

Fig. 1. The principle of the ultrasound active system.

However, after passing through the underwater media, the power and the low noise amplifiers, the emitted waveform is deformed. This happens also due to the frequency varying electric impedance of the ultrasound transducers. As a consequence, the results, after the match filter detection at the reception, are less accurate. In this paper, we introduce an 
automatic method for reference selection in order to provide a more robust fish detection result.

\section{REFERENCE SELECTION PROCEDURE}

In many signal processing applications the analyzed signals are nonstationary in the sense that the frequency changes over time and are comprised of multiple components each having its particular instantaneous frequency law (IFL). Most of the times the phase function of an analytic non-stationary component can be described by a parametric model. If there is no a priori information of the signals nature, a widely employed model is the polynomial phase signal (PPS) model based on the Weierstrass approximation theorem.

The proposed approach is based on time warping [4] the given signal with different parametric functions and identifying for which parameters the warped signal has the best spectral concentration [5]. The cost function used for evaluating the spectral concentration is derived from the measures designed to evaluate time-frequency distributions concentration. Full detail of the range acoustic autofocusing algorithm [6] is illustrated on Fig. 2.

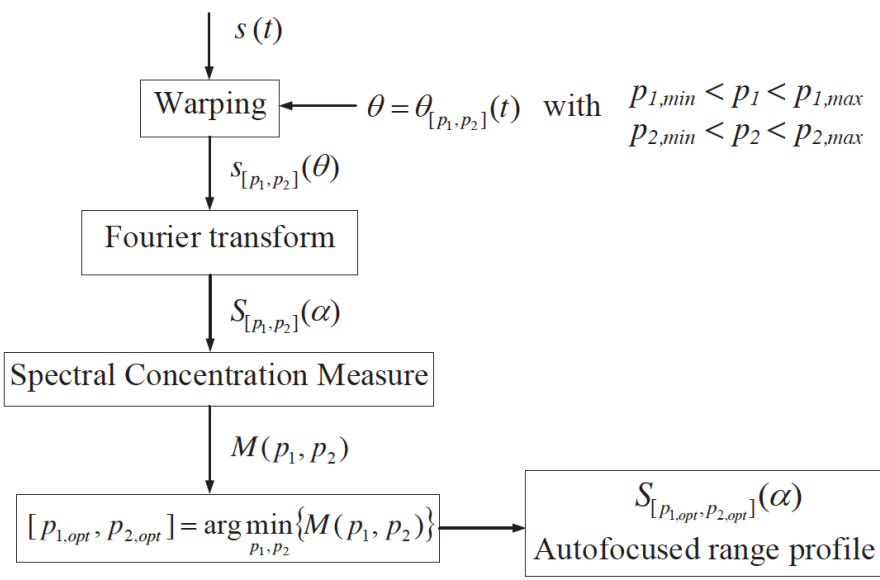

Fig. 2. Range acoustic autofocusing algorithm diagram for a 2-parameter nonlinearity model.

The acoustic autofocusing approach has the main advantage that it does not need a particular reference target to estimate the correction nonlinearities of the acoustic channel and it works in the presence of multiple reflective targets such as fishes. However, the number of model parameters is limited from an operational point of view: it is not practical to minimize a cost function of too many variables. In our case three is enough.

For the ultrasound wild salmon monitoring system under study, the received frequency-voltage characteristic can be approximated by a third order polynomial expression. Applying the proposed algorithm on the received signal, the nonlinearity coefficients are determined and the range profile computed by match filtering with the signal warped in the optimal basis as reference.

The only question remains how to distinguish between the unperturbed reference signal and the revived signal affected by the fish passages. This is done by computing histograms (empirical probability density function) with the LFI coefficients obtained from different realizations of the received signal for each acoustic barrier. By considering the fish passages as sparse events, we obtain a bi-modal histogram shape on which conventional histogram thresholding methods such as [7] can be applied.

\section{RESULTS}

The experimental setup is composed by one acoustic barrier equipped with Ultran GS-30 ultrasound transducers. The transducer transfer function is shown on Fig. 3. One can notice three different frequency bands with linear phase: around 36 $\mathrm{KHz}$, around $110 \mathrm{KHz}$ and around $460 \mathrm{KHz}$. The emitted waveform is a linear chirp in the frequency band $400 \mathrm{KHz}$ to $500 \mathrm{KHz}$. The measured directivity diagram and the static characteristics in all three operating frequency bands of the ultrasound transducers are illustrated on Fig. 4.
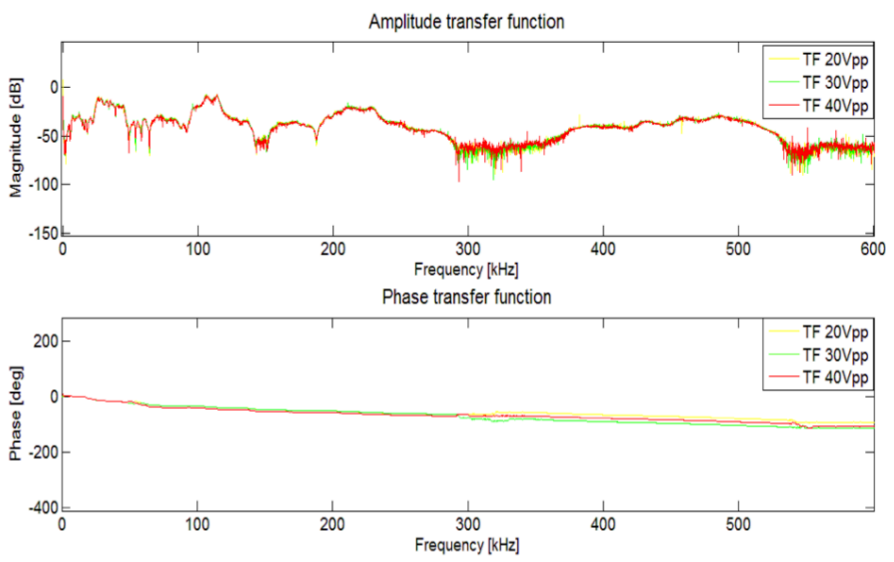

Fig. 3. Ultran GS-30 ultrasound transducers transfer function.

Fig. 5-(a) illustrates the obtained histograms of the first and the second dictionary coefficients. One can notice a bimodal empirical probability density function in both cases. Fig. 5(b) shows the comparison between the range profile obtained by match filtering with the emission (in red) and with the estimated reference (in blue): the detection in this range profile is improved by $30 \mathrm{~dB}$ using the proposed reference selection scheme.

Often, multiple acoustic echoes can be encountered in the same range profile. Fig. 6-(a) illustrates a full range profile which presents at least four indirect paths. One question is rising, namely whether we should use these reflections in order to improve the detection result after match filtering or not (the improvement is marginal). The proposed acoustic autofocusing algorithm is used to take into account the first two reflected paths. Indeed, the reflections can be considered as harmonics of the direct path in the proposed approach. The obtained result is presented on Fig. 6-(b). One can observe that the practical detection improvement by considering the first two indirect paths is quite marginal for our study. 


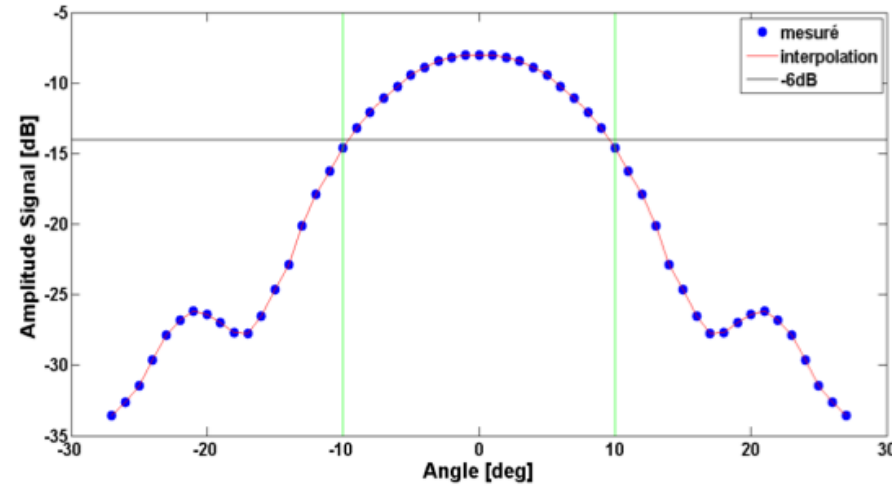

(a)

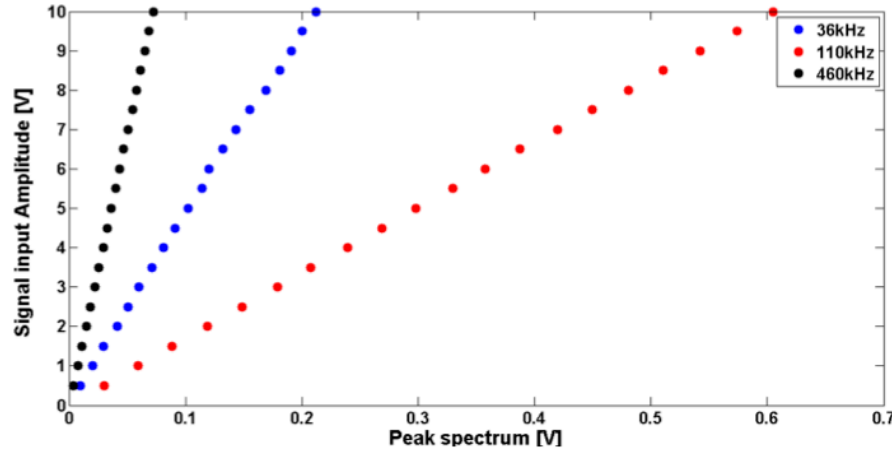

(b)

Fig. 4. Ultran GS-30 ultrasound transducers: (a) measured directivity diagram, (b) static characteristics in all three frequency bands.

The smolt detection results are illustrated on Fig. 7. One can notice that the smolts detection can be directly performed after match filtering. Indeed, when a smolt is passing through the acoustic barrier, a decrease appears in the focused received signal. The principle is graphically explained on Fig. 8-(a),(b).

Finally, an interesting phenomena is occurring when the smolt is passing in the proximity of the acoustic barrier (e.g. as in Fig. 8-(c)): due to indirect path reflexion, the focused received signal level is increased.

\section{CONCLUSION}

The general automatic reference selection procedure presented in this paper offers an alternative option to monitor wild salmon migration in turbulent underwater environments. The main advantages of the proposed algorithm are improved detection capabilities at the reception, the improved resolution and the opportunity for automatic in situ acoustic channel equalization. Future studies include developing full identification and tracking capabilities of different fish types.

\section{REFERENCES}

[1] C. Spampinato, Y. H. Chen-Burger, G. Nadarajan, and R. Fisher, "Detecting, tracking and counting fish in low quality unconstrained underwater videos," in Proceedings of the 3rd Int. Conf. on Computer Vision Theory and Applications (VISAPP), 2008, vol. 2, pp. 514-519.

[2] I. P. Smith, A. D. F. Johnstone, and D. A. Dunkley, "Development of a "weir-less" electrode array for a resistivity fish counter: results of field trials in 1993," Tech. Rep. 04/94, Scottish Fisheries Research Services, 1994.
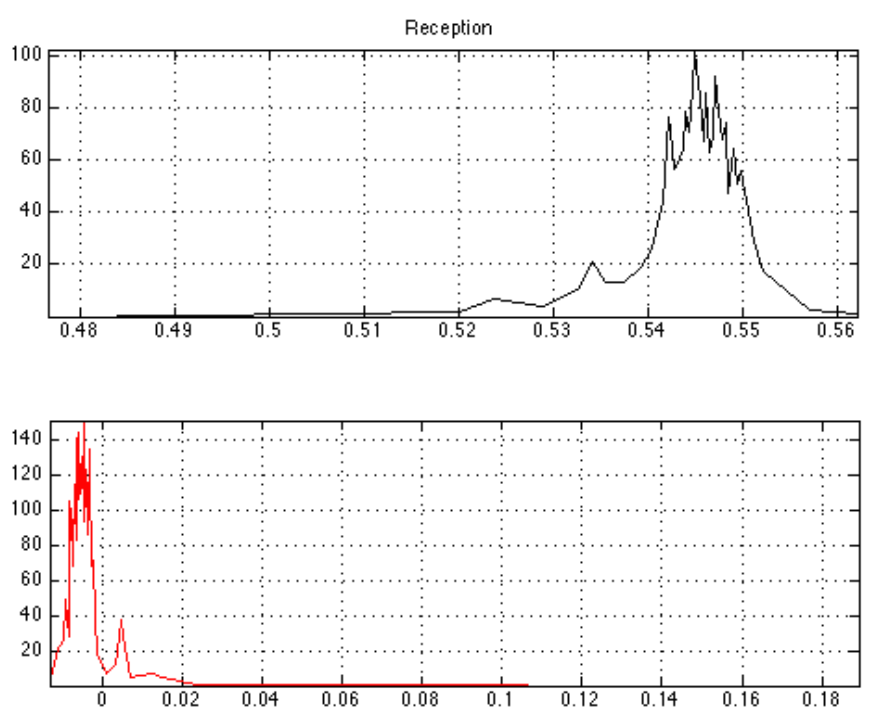

(a)

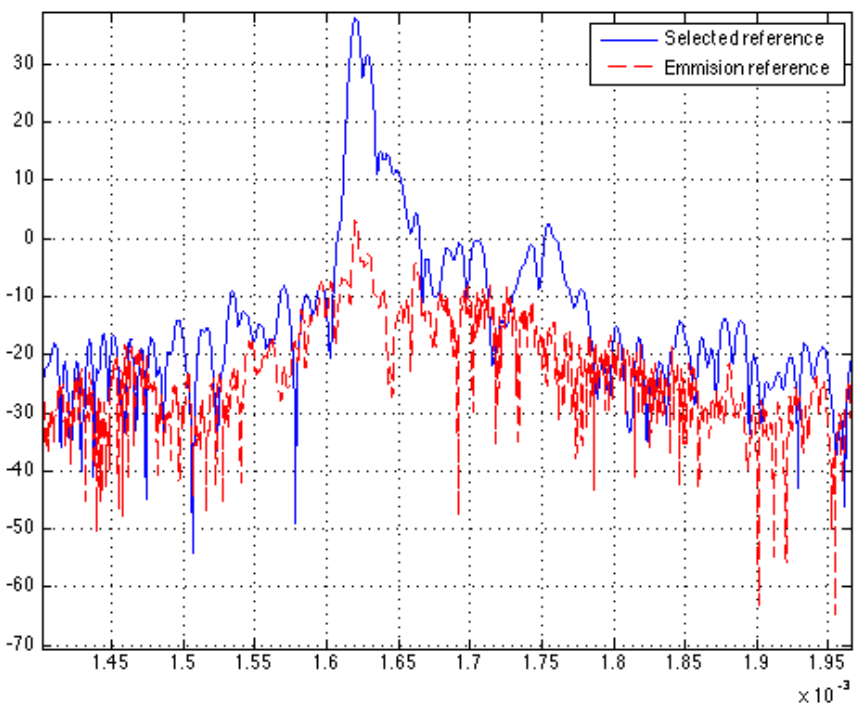

(b)

Fig. 5. (a) histograms of the first and the second dictionary coefficients, (b) obtained range profile - direct path.

[3] H. P. An, B. Lundgren, B. Stage, and J. A. Jensen, "Ultrasound backscatter from free-swimming fish at $1 \mathrm{MHz}$ for fish identification," in Proceedings of the IEEE International Ultrasonics Symposium (IUS), 2012, pp. 1477-1480.

[4] H. Shen and A. Papandreou-Suppappola, "Wideband timevarying interference suppression using matched signal transforms," IEEE Transactions on Signal Processing, vol. 53, no. 7, pp. 2607-2612, 2005.

[5] L. Stankovic, "A measure of some time-frequency distributions concentration," Signal Processing, vol. 81, no. 3, pp. 621-631, 2001.

[6] A. Anghel, G. Vasile, C. Ioana, R. Cacoveanu, and S. Ciochina, "Modelbased parameter estimation of non-stationary signals using time warping and a measure of spectral concentration," in Proceedings of the IEEE International Conference on Acoustics, Speech, and Signal Processing, Brisbane, Australia, 2015, p. 5 pages.

[7] N. Otsu, "A threshold selection method from gray-level histograms," IEEE Trans. Sys., Man., Cyber., vol. 9, pp. 62-66, 1979. 


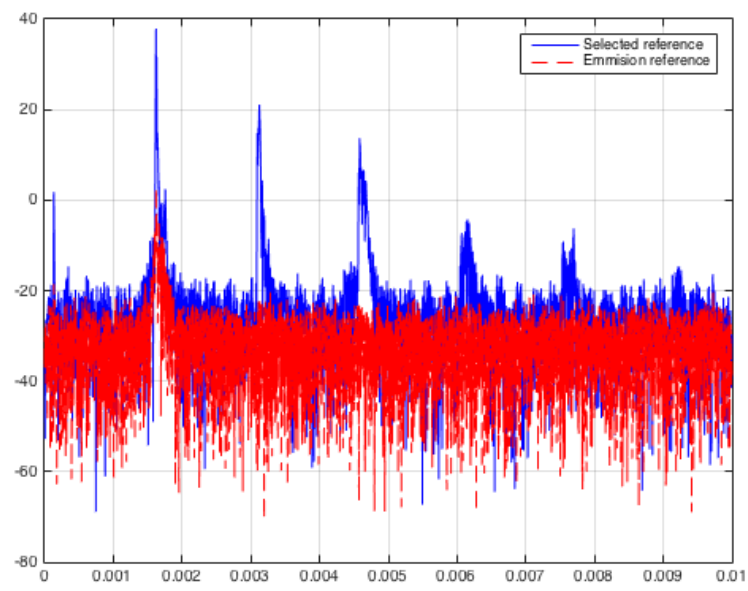

(a)

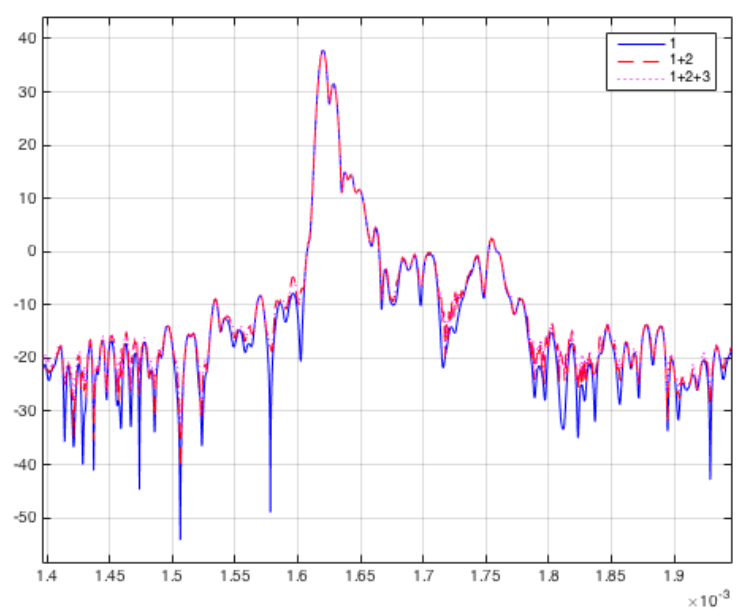

(b)

Fig. 6. (a) obtained range profile - direct path and indirect paths, (b) range acoustic autofocusing using the direct path and the first two indirect paths.

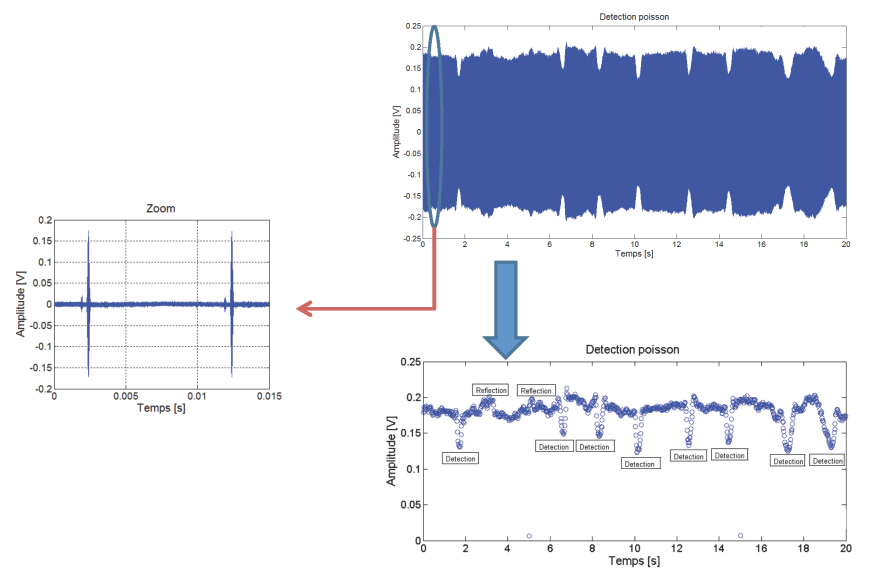

Fig. 7. An example of smolt detection result.
Fish

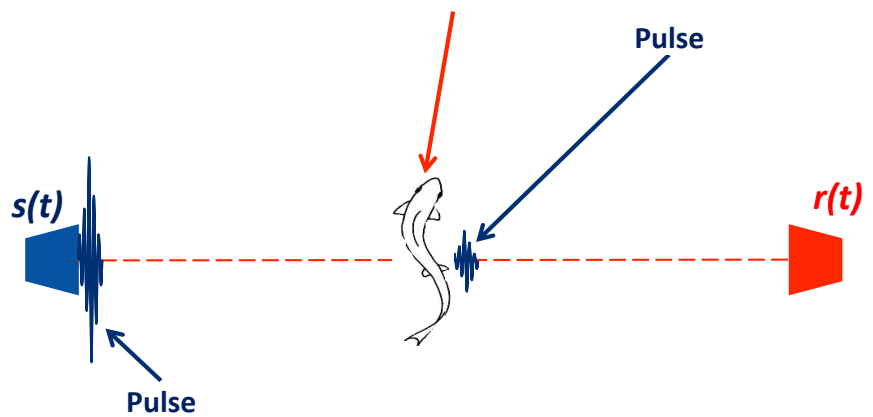

(a)
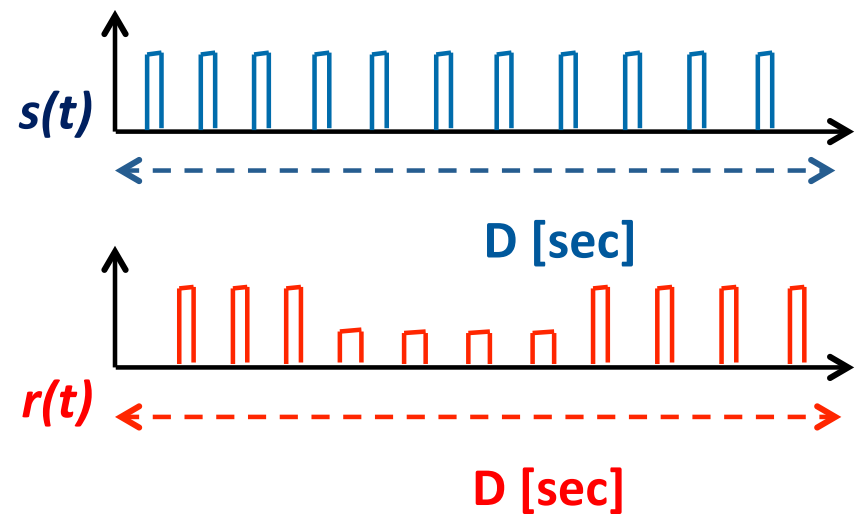

(b)

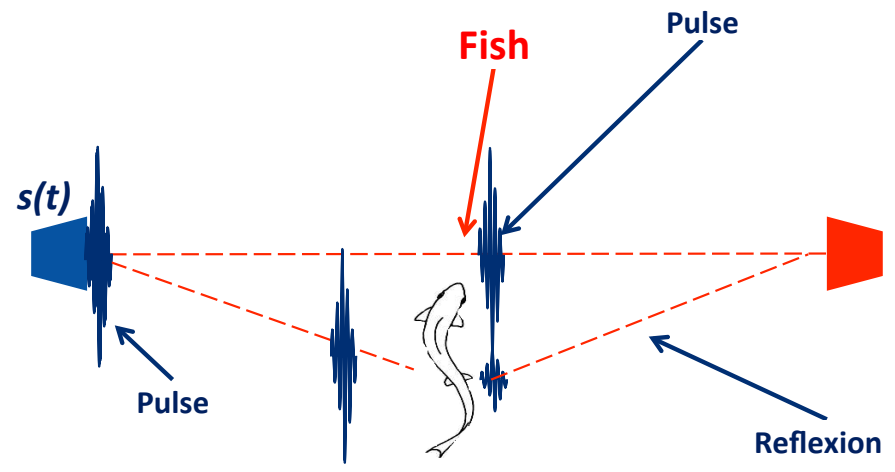

(c)

Fig. 8. (a) acoustic channel obstruction when a smolt is passing through the barrier, (b) impact of the smolt passage on the focused received signal, (c) acoustic channel perturbation (by reflexion) when a smolt is passing in the proximity of the barrier. 